\section{Ciência e saúde: desafios ao patrimônio mundial}

\section{Science and health: challenges facing World Heritage}

\author{
Marcos José de Araújo Pinheiro \\ 'Vice-diretor de Patrimônio Cultural e Divulgação Científica, \\ Casa de Oswaldo Cruz/Fiocruz. \\ Rio de Janeiro - RJ - Brasil \\ orcid.org/0000-0002-0721-9828 \\ marcos.pinheiro@fiocruz.br \\ José do Nascimento Jr.ii \\ ii Assessor da Direção, Casa de Oswaldo Cruz/Fiocruz. \\ Rio de Janeiro - RJ - Brasil \\ orcid.org/0000-0001-6918-1557 \\ jotanascimentojr@gmail.com
}

Recebido em 8 ago. 2019.

Aprovado em 30 dez. 2019.
PINHEIRO, Marcos José de Araújo; NASCIMENTO JR., José do. Ciência e saúde: desafios ao patrimônio mundial História, Ciências, Saúde - Manguinhos, Rio de Janeiro, v.27, n.2, abr.-jun. 2020, p.637-656.

\section{Resumo}

Desde a aprovação, em 1972, da Convenção para a Proteção do Patrimônio Mundial, a Unesco - agência das Nações Unidas para a educação, ciência e cultura - avalia as candidaturas e atualiza a Lista do Patrimônio Mundial. Em sua procura de ampliar o espectro de tipos de patrimônio reconhecidos como de valor universal excepcional, na perspectiva de reconhecimento da diversidade humana e de sua produção sociocultural, a Unesco vem incorporando novas categorias e temas. Pretende-se avaliar os resultados alcançados pela Unesco em sua indicação de bens mundiais, à luz das diferenças regionais e de possíveis lacunas de reconhecimento da diversidade cultural, do cotidiano e da produção humana, como o patrimônio cultural relativo às ciências e à saúde.

Palavras-chave: patrimônio mundial; patrimônio cultural; patrimônio cultural da saúde; políticas culturais; ciências e saúde.

\section{Abstract}

Since 1972, when the Convention concerning the Protection of the World Cultural and Natural Heritage was adopted, the United Nations Educational, Scientific and Cultural Organization (UNESCO) has assessed applications and added properties to its World Heritage List. In a quest to broaden the scope of heritage of outstanding universal value, giving due recognition to human diversity and sociocultural expression, UNESCO has introduced new categories and topics. The results it has attained in its listing of heritage sites are evaluated in the light of regional differences and potential gaps in the recognition of cultural diversity and everyday human activities and production as health and scientific heritage.

Keywords: world heritage; cultural heritage; health heritage; cultural policies; science and health. 


\section{O patrimônio mundial: breve histórico}

No contexto internacional, as preocupações com as ameaças aos bens culturais durante conflitos armados apareceram já em 1874 na reunião de representantes de Estados europeus, em Bruxelas, que resultou na Declaração de Bruxelas, e ressurgiram posteriormente, quando realizadas as Convenções de Haia de 1899 e de 1907, pautadas pelos constantes conflitos em solo europeu. Em 1935, foi assinado o Pacto de Röerich (Instituto Röerich..., s.d.), como ficou conhecido o Tratado para Proteção de Todas as Instituições Artísticas e Científicas e Monumentos Históricos, em homenagem a Nicholas Röerich, que, entre outras ações em prol da valorização da paz e da arte, criou em 1929 um projeto para um pacto de proteção aos "tesouros da cultura". O Pacto de Röerich foi concebido com base nos debates das comissões das sessões da Conferência Pan-americana, ou Conferência Internacional dos Estados Americanos, como também era nomeada, e dos documentos informativos elaborados por Röerich. Foi postulado por todos os Estados representados na sétima Conferência Internacional dos Estados Americanos, realizada em Montevidéu, em 1933, com a ideia de que os bens culturais, que "formam o tesouro cultural dos povos, devem ser respeitados e protegidos em tempos de guerra e de paz" (Fiankan-Bokonga, out.-dez. 2017, p.7). O tratado propôs que os monumentos históricos, museus, instituições científicas, artísticas, educacionais e culturais, incluindo seus profissionais, passassem a ser considerados neutros e, como tal, respeitados e protegidos pelos beligerantes. O pacto foi firmado pelas 21 nações pertencentes à União Pan-americana, tendo, na ocasião, os EUA como seu avalista, com a presença do então presidente Franklin Delano Roosevelt. O Brasil foi representado por Osvaldo Aranha, que o assinou em 15 de abril de 1935.

Esse foi um importante momento entre as duas grandes guerras que objetivou criar mecanismos de valorização de bens culturais e da cultura com vistas à paz entre as nações. Posteriormente, com a criação da Organização das Nações Unidas para a Educação, a Ciência e a Cultura (Unesco), em 1945, ampliaram-se os empenhos para discutir as demandas subsequentes às duas guerras mundiais, e, em prol disso, "a Unesco se comprometeu para que o tema sobre a proteção e defesa dos bens culturais fosse retomado e debatido em profundidade" (Guedes, 2018, p.26). Em 1948, motivada pelas experiências de saques ocorridas na guerra terem-se estendido às cidades, sob a forma de pilhagens ordenadas de obras de arte e museus, houve a proposta, junto à Unesco, a partir de iniciativa dos Países Baixos, de criação de um novo tratado internacional sobre a proteção de bens culturais em tempos de guerra, o que motivou a elaboração da Convenção para a Proteção dos Bens Culturais em Caso de Conflito Armado, aprovada em Haia, em 1954 (Fiankan-Bokonga, out-dez. 2017, p.8), aparecendo pela primeira vez em acordos internacionais "de forma clara e objetiva a expressão bens culturais, quando elaborado um conclave especificamente para debater esse assunto" (Guedes, 2018, p.4).

A Unesco, estimulada pela decisão do Egito de construir a Represa de Assuã, que inundaria o vale do Alto Nilo e muitos monumentos de 3 mil anos de idade (Fiankan-Bokonga, outdez. 2017, p.8), lançou em 1954 uma campanha internacional para salvaguardar esses monumentos. Para a realocação de vários bens que seriam inundados, realizou-se uma grande mobilização internacional, conhecida como Campanha de Núbia, envolvendo mais 
de cinquenta países que contribuíram para a preservação desses sítios. Essa mobilização inspirou a Unesco a criar mecanismos que, abarcando o conjunto dos Estados-membros, resultaram na Convenção para a Proteção do Patrimônio Mundial, Cultural e Natural, ou Convenção de Paris de 1972, promulgada pela Conferência Geral da Unesco de 23 de novembro de 1972, em Paris.

Antes dessa convenção houve uma longa trajetória de diferentes instrumentos (Código Lieber de 1863; Conferências de Paz de Haia de 1899 e 1907; Declaração de Bruxelas de 1874; Pacto de Röerich de 1935; Convenção de Haia de 1954; Norma de Quito de 1967; Recomendação de Paris de 1968; Convenção de Paris de 1970; Declaração de Estocolmo de 1972) que, ao longo do tempo, avançaram nos processos de institucionalização e construção do conceito de patrimônio mundial e de sua proteção, conformando ambientes propícios, consensos, bem como constituindo acordos nos cânones da Unesco e de outras organizações com fins de proteger e valorizar os patrimônios culturais e naturais cada vez mais sob ameaças advindas não só da ação do tempo, agravadas por fenômenos ambientais, como também de transformações do cotidiano socioeconômico ou por conflitos armados. Documentos como o Código Lieber, voltado para normatizar os conflitos durante a Guerra de Secessão nos EUA, segundo Guedes (2018, p.5), de abrangência apenas em solo americano, mas que acabou por se transformar em modelo para leis na Europa, a ponto de influenciar a Declaração de Bruxelas, uma das primeiras tentativas de incorporação das leis de guerra e de proteção aos monumentos e obras de arte; ou como a Norma de Quito de 1967, no âmbito da Organização dos Estados Americanos (OEA), com caráter apenas indicativo, conformaram o ambiente e prepararam o caminho que levou à Convenção de Paris de 1972.

Essa convenção de 1972 tem como caraterística a salvaguarda do patrimônio mundial, cultural e natural, conceituando: fundos de preservação; condições e modalidades de assistência internacional; e programas educativos. Com ênfase, expressa a compreensão de que a proteção de tais áreas não poderia ser efetuada unicamente em escala nacional, devido à magnitude dos meios necessários para esse procedimento, que, não raras vezes, extrapolavam os recursos econômicos, científicos e tecnológicos dos países. O número de nações ao redor do mundo que assinaram a Convenção do Patrimônio Mundial no período de 2009 a 2019 subiu de 139 para 193, perfazendo 167 Estados-parte com bens inscritos como patrimônio do mundo, e restando apenas 26 sem alguma nomeação até 2019 (Unesco, 2019a).

\section{Avaliações sobre a Lista do Patrimônio Mundial e sua representatividade}

A aprovação de um bem cultural, natural, misto ou uma paisagem cultural como patrimônio mundial com sua subsequente inscrição na Lista do Patrimônio Mundial ou na Lista do Patrimônio Mundial em Perigo, segundo o que rege a convenção, é o reconhecimento conferido pela Unesco de ele possuir importância única para o mundo e a humanidade; esse reconhecimento atribui à Unesco e aos Estados-parte diretamente envolvidos responsabilidades com vistas a estabelecer salvaguardas para garantir sua preservação às gerações futuras. Essas questões apontam para um movimento contemporâneo permanente e dinâmico de atualização dos conceitos sobre patrimônio, incorporando a cada momento novas temáticas à luz do desenvolvimento e das complexidades dos fazeres humanos. 
O documento "Orientações técnicas para aplicação da convenção do patrimônio mundial"1 (Unesco, 2017), produzido pela Unesco e pelo World Heritage Centre com o objetivo de orientar as aplicações à Convenção do Patrimônio Mundial, atualiza periodicamente os procedimentos para submissão de candidaturas pelos Estados-parte, observados os critérios para avaliação do Valor Universal Excepcional (VUE), das condições quanto à autenticidade e integridade e da proteção e gestão. Tendo como base a Declaração de Budapeste sobre o Patrimônio Mundial, de 2002, a partir da revisão de 2008 esse documento de orientações técnicas assumiu apenas cinco objetivos como estratégicos, que ficaram conhecidos como os Cinco C, ${ }^{2}$ revelando a preocupação por parte da Unesco de mais aproximação com a sociedade, explicitada por meio de objetivos que visam "incrementar a sensibilização do público, a participação e o apoio ao Patrimônio Mundial por meio da 'Comunicação'”, e "valorizar o papel das 'Comunidades' na aplicação da Convenção do Patrimônio Mundial” (Unesco, 2017, p.13; destaques nossos).

É importante observar quanto e como os princípios que fundamentam a proposta de patrimônio mundial, em especial do patrimônio cultural, aproximam-se ou não daqueles que conformam os conjuntos de significados identitários, sociais, culturais, históricos e afetivos de diferentes comunidades e territórios. O início para essa reflexão passa pela avaliação do significado de valor universal excepcional (VUE). As orientações técnicas definem o VUE como "uma importância cultural e/ou natural tão excepcional que transcende as fronteiras nacionais e se reveste de uma importância comum para as gerações atuais e futuras de toda a humanidade" (Unesco, 2017, p.19), o que a princípio determina que o valor do bem não se restringe a uma nação e a um contexto histórico e tem significados em outros territórios e gerações. O que se observa, entretanto, é que, desde o estabelecimento da Convenção do Patrimônio Mundial em 1972, 47\% dos bens declarados como patrimônio mundial estão localizados na Europa e América do Norte, conforme mostra-nos a Tabela 1, destacandose que esse número sobe para 52\% quando se trata de bens culturais inscritos. Ressalta-se que, dos cinco países com mais bens reconhecidos como patrimônio do mundo, ${ }^{3}$ quatro são europeus, e o país com maior número de bens culturais é a Itália.

As análises que se seguem tomam como base a avaliação de bens inscritos como patrimônio do mundo pelas regiões, conforme denominação da Unesco: África; América Latina e Caribe; Ásia e Pacífico; Europa e América do Norte; Países Árabes. Consideram dois períodos para estudo, compreendendo o que denominamos série histórica, de 1978 a 2019, com todos os bens inscritos; e o que abarca os últimos dez anos (2010 a 2019). A Tabela 2 apresenta o número total de bens inscritos em valores absolutos e percentuais, o que inclui os patrimônios cultural, natural, misto e a paisagem cultural, por região nos últimos dez anos. A Tabela 3 exerce a mesma função da anterior, apenas destacando o que tange ao patrimônio cultural. A Tabela 4 traz os dados comparativos em valores percentuais entre os dois períodos (série histórica e últimos dez anos) por região, de modo a se poder avaliar tendências e comportamentos. Cabe ressaltar que as informações e os dados para elaboração das tabelas trabalhadas neste artigo foram obtidos no sítio oficial da Unesco na internet, na área relativa ao World Heritage Centre (WHC), em especial os dados e as ferramentas de pesquisa avançada disponibilizados por esse centro (Unesco, 2019a). 
Tabela 1: Bens inscritos como patrimônio do mundo, 1978 a 2019

\begin{tabular}{lccccc}
\hline Região & Cultural & Natural & Misto & Total & $\begin{array}{c}\text { Percentual } \\
\text { sobre o total }\end{array}$ \\
\hline África & 53 & 38 & 5 & 96 & 8,6 \\
\hline América Latina e Caribe & 96 & 38 & 8 & 142 & 12,7 \\
\hline Ásia e Pacífico & 189 & 67 & 12 & 268 & 23,9 \\
\hline Europa e América do Norte & 453 & 65 & 11 & 529 & 47,2 \\
\hline Países Árabes & 78 & 5 & 3 & 86 & 7,7 \\
\hline Total & 869 & 213 & 39 & 1121 & 100 \\
\hline
\end{tabular}

Fonte: Tabela traduzida e adaptada pelos autores a partir de dados da Unesco World Heritage, disponível em: <https://whc.unesco.org/ en/list/stat/\#s10>. Acesso em: 24 out. 2019.

A hegemonia da região Europa e América do Norte observada a partir dos dados da Tabela 1 é confirmada como tendência atual segundo os dados das Tabelas 2 e 3, principalmente em relação às regiões África, América Latina e Caribe e Países Árabes, ainda que em 1994 o Comitê do Patrimônio Mundial tenha lançado a estratégia global com o objetivo de garantir que a Lista do Patrimônio Mundial refletisse a diversidade cultural e natural do mundo de VUE, e que, em sua $28^{a}$ sessão em 2004, o comitê tenha revisado as análises mais recentes da Lista do Patrimônio Mundial e das Listas Provisórias preparadas pelas organizações consultivas em bases regionais, cronológicas, geográficas e temáticas, a fim de avaliar o progresso da estratégia global. No caso do patrimônio cultural, objeto de nosso estudo, o Conselho Internacional dos Monumentos e dos Sítios (Icomos) observou que as razões para as lacunas de representação na Lista do Patrimônio Mundial dividiam-se em categorias estruturais, relacionadas ao processo de indicação a Patrimônio Mundial, e ao gerenciamento e proteção de propriedades culturais; e categorias qualitativas, relacionadas à forma como os bens culturais são identificados e avaliados (Unesco, 2019b).

Tabela 2: Número total de bens inscritos (cultural, natural, misto e paisagem cultural) como patrimônio do mundo por região, 2010 a 2019

\begin{tabular}{|c|c|c|c|c|c|c|c|c|c|c|c|}
\hline \multirow{2}{*}{ Ano } & \multirow{2}{*}{$\begin{array}{l}\text { Número } \\
\text { de bens } \\
\text { inscritos }\end{array}$} & \multicolumn{2}{|c|}{$\begin{array}{c}\text { Europa e América } \\
\text { do Norte }\end{array}$} & \multicolumn{2}{|c|}{ Ásia e Pacífico } & \multicolumn{2}{|c|}{$\begin{array}{c}\text { América Latina e } \\
\text { Caribe }\end{array}$} & \multicolumn{2}{|c|}{ Países Árabes } & \multicolumn{2}{|c|}{ África } \\
\hline & & Total & $\%$ & Total & $\%$ & Total & $\%$ & Total & $\%$ & Total & $\%$ \\
\hline 2010 & 21 & 5 & 23,8 & 12 & 57,1 & 3 & 14,3 & 1 & 4,8 & - & - \\
\hline 2011 & 25 & 7 & 28 & 7 & 28 & 3 & 12 & 4 & 16 & 4 & 16 \\
\hline 2012 & 26 & 10 & 38,5 & 8 & 30,8 & 1 & 3,8 & 3 & 11,5 & 4 & 15,4 \\
\hline 2013 & 19 & 7 & 36,8 & 8 & 42,1 & 1 & 5,3 & 1 & 5,3 & 2 & 10,5 \\
\hline 2014 & 26 & 10 & 38,5 & 10 & 38,5 & 2 & 7,7 & 3 & 11,5 & 1 & 3,8 \\
\hline 2015 & 24 & 12 & 50 & 7 & 29,2 & 3 & 12,5 & 2 & 8,3 & - & - \\
\hline 2016 & 21 & 6 & 28,6 & 8 & 38,1 & 4 & 19 & 2 & 9,5 & 1 & 4,8 \\
\hline 2017 & 21 & 8 & 38,1 & 7 & 33,3 & 2 & 9,5 & 1 & 4,8 & 3 & 14,3 \\
\hline
\end{tabular}




\begin{tabular}{|c|c|c|c|c|c|c|c|c|c|c|c|}
\hline \multirow{2}{*}{ Ano } & \multirow{2}{*}{$\begin{array}{l}\text { Número } \\
\text { de bens } \\
\text { inscritos }\end{array}$} & \multicolumn{2}{|c|}{$\begin{array}{c}\text { Europa e América } \\
\text { do Norte }\end{array}$} & \multicolumn{2}{|c|}{ Ásia e Pacífico } & \multicolumn{2}{|c|}{$\begin{array}{c}\text { América Latina e } \\
\text { Caribe }\end{array}$} & \multicolumn{2}{|c|}{ Países Árabes } & \multicolumn{2}{|c|}{ África } \\
\hline & & Total & $\%$ & Total & $\%$ & Total & $\%$ & Total & $\%$ & Total & $\%$ \\
\hline 2018 & 19 & 8 & 42,1 & 5 & 26,3 & 2 & 10,5 & 2 & 10,5 & 2 & 10,5 \\
\hline 2019 & 29 & 15 & 51,7 & 10 & 34,5 & 1 & 3,4 & 2 & 6,9 & 1 & 3,4 \\
\hline Total & 231 & 88 & 38,1 & 82 & 35,5 & 22 & 9,5 & 21 & 9,1 & 18 & 7,8 \\
\hline
\end{tabular}

Fonte: Tabela produzida pelos autores a partir dos dados disponíveis em: <https://whc.unesco.org/en/list/stat/\#s10>. Acesso em: 24 out. 2019.

Para justificar as candidaturas quanto ao VUE é necessário que elas apresentem suas argumentações com base em alguns dos dez critérios estabelecidos nas Orientações Técnicas (Unesco, 2017), sendo os seis primeiros relativos aos bens culturais, e os restantes aos bens naturais. Nos casos de bens mistos e de paisagens culturais, há que relacionar critérios do primeiro segmento com o do segundo. Avaliando-se os seis critérios relacionados aos bens culturais observa-se que, em tese, possibilitam atender a candidaturas que espelhem maior diversidade cultural.

Tabela 3: Número de bens culturais inscritos como patrimônio do mundo por região, 2010 a 2019

\begin{tabular}{|c|c|c|c|c|c|c|c|c|c|c|c|}
\hline \multirow{2}{*}{ Ano } & \multirow{2}{*}{$\begin{array}{c}\text { Bens } \\
\text { culturais } \\
\text { inscritos }\end{array}$} & \multicolumn{2}{|c|}{$\begin{array}{c}\text { Europa e América } \\
\text { do Norte }\end{array}$} & \multicolumn{2}{|c|}{ Ásia e Pacífico } & \multicolumn{2}{|c|}{$\begin{array}{c}\text { América Latina e } \\
\text { Caribe }\end{array}$} & \multicolumn{2}{|c|}{ Países Árabes } & \multicolumn{2}{|c|}{ África } \\
\hline & & Cultural & $\%$ & Cultural & $\%$ & Cultural & $\%$ & Cultural & $\%$ & Cultural & $\%$ \\
\hline 2010 & 15 & 2 & 13,3 & 9 & 60 & 3 & 20 & 1 & 6,7 & - & - \\
\hline 2011 & 21 & 7 & 33,3 & 5 & 23,8 & 3 & 14,3 & 3 & 14,3 & 3 & 14,3 \\
\hline 2012 & 20 & 9 & 45 & 5 & 25 & 1 & 5 & 3 & 15 & 2 & 10 \\
\hline 2013 & 14 & 6 & 42,9 & 6 & 42,9 & - & - & 1 & 7,1 & 1 & 7,1 \\
\hline 2014 & 21 & 9 & 42,9 & 7 & 33,3 & 2 & 9,5 & 3 & 14,3 & - & - \\
\hline 2015 & 23 & 12 & 52,2 & 7 & 30,4 & 2 & 8,7 & 2 & 8,7 & - & - \\
\hline 2016 & 12 & 5 & 41,7 & 4 & 33,3 & 3 & 25 & - & - & - & - \\
\hline 2017 & 18 & 8 & 44,4 & 5 & 27,8 & 1 & 5,6 & 1 & 5,6 & 3 & 16,7 \\
\hline 2018 & 13 & 6 & 46,2 & 4 & 30,8 & - & - & 2 & 15,4 & 1 & 7,7 \\
\hline 2019 & 24 & 13 & 54,2 & 8 & 33,3 & - & - & 2 & 8,3 & 1 & 4,2 \\
\hline Total & 181 & 77 & 42,5 & 60 & 33,1 & 15 & 8,3 & 18 & 9,9 & 11 & 6,1 \\
\hline
\end{tabular}

Fonte: Tabela produzida pelos autores a partir dos dados disponíveis em: <https://whc.unesco.org/en/list/stat/\#s10>. Acesso em: 24 out. 2019.

Na prática, os esforços previstos na estratégia global ainda não são capazes de propiciar maior pluralidade tal como almejado pela própria Unesco, prevalecendo a tendência de maior número de representações dos países da região Europa e América do Norte, como se pode observar na Tabela 4. A representação hegemônica dessa região, contudo, reduziu-se de $47,1 \%$, na série histórica de 1978 a 2019, para 38,1\%, no período entre 2010 e 2019. Quanto aos números referentes unicamente aos bens culturais reconhecidos, a Tabela 4 exibe 42,5\% 
nos últimos dez anos, e 52,1\% na série histórica. Os últimos dez anos parecem expressar um avanço na estratégia de refletir a diversidade, com redução percentual de representações da região com maior número de patrimônios do mundo. Pode-se também observar, na mesma tabela, crescimento significativo de indicações referentes à região Ásia e Pacífico, com $23,86 \%$ do total e $21,7 \%$ de bens culturais no período de 1978 a 2019, passando a $35,5 \%$ e 33,1\%, respectivamente, no período de 2009 a 2019. Os valores das regiões América Latina e Caribe e África variaram negativamente tanto para o total de bens inscritos como para bens culturais, nos dois períodos de comparação, enquanto na região Países Árabes houve variação positiva de 17,3\% e 10,9\%, respectivamente, embora permaneça como menor representação percentual do total de bens inscritos como patrimônio do mundo e como terceira menor representação de bens culturais, acima apenas, nesse caso, da África e de América Latina e Caribe.

Tabela 4: Percentual e variação percentual de bens culturais inscritos como patrimônio do mundo por região, períodos 1978-2019 e 2010-2019

\begin{tabular}{|c|c|c|c|c|c|c|}
\hline Região & $\begin{array}{l}\text { Total no } \\
\text { período } \\
1978-2019 \\
\text { (\%) }\end{array}$ & $\begin{array}{l}\text { Total no } \\
\text { período } \\
2010-2019 \\
(\%)\end{array}$ & $\begin{array}{l}\text { Variação } \\
\text { no total } \\
\text { de bens } \\
\text { inscritos (\%) }\end{array}$ & $\begin{array}{l}\text { Bens } \\
\text { culturais } \\
\text { no período } \\
1978-2019 \\
(\%) \\
\end{array}$ & $\begin{array}{l}\text { Bens } \\
\text { culturais } \\
\text { no período } \\
2010-2019 \\
(\%)\end{array}$ & $\begin{array}{l}\text { Variação } \\
\text { de bens } \\
\text { culturais } \\
\text { inscritos (\%) }\end{array}$ \\
\hline África & 8,6 & 7,8 & $-8,9$ & 6,1 & 6,1 & $-0,2$ \\
\hline América Latina e Caribe & 12,7 & 9,5 & $-25,2$ & 11,1 & 8,3 & $-25,7$ \\
\hline Ásia e Pacífico & 23,9 & 35,5 & 48,8 & 21,7 & 33,1 & 52,6 \\
\hline $\begin{array}{l}\text { Europa e América do } \\
\text { Norte }\end{array}$ & 47,1 & 38,1 & $-19,1$ & 52,1 & 42,5 & $-18,3$ \\
\hline Países Árabes & 7,8 & 9,1 & 17,3 & 9 & 9,9 & 10,9 \\
\hline Total & 100 & 100 & & 100 & 100 & \\
\hline
\end{tabular}

Fonte: Tabela produzida pelos autores a partir dos dados disponíveis em: <https://whc.unesco.org/en/list/stat/\#s10>. Acesso em: 24 out. 2019.

Essa variação no período carece de investigação aprofundada sobre o que de fato gerou tal transformação; o quanto ela reflete a busca de ampliação do espectro de representações ou fatores de outra natureza, como geopolíticos e econômicos; se será mantida como tendência aos próximos anos; e qual o papel efetivo dos Planos de Ação Sub-regionais em relação à baixa representação de bens culturais inscritos pelas regiões África e América Latina e Caribe. De todo modo, cabe lembrar que, apesar de ser necessário comprovar o VUE, ele por si só não é suficiente para a candidatura, uma vez que há que considerar condições como autenticidade, integridade, além da gestão do bem. Uma investigação com maior aprofundamento deve considerar todos esses aspectos, além da quantidade de candidaturas anuais por região e os índices de aprovação. Por isso, é oportuno e de relevância ímpar lembrar Aloisio Magalhães discorrendo sobre países velhos e novos, ricos e pobres, em sua intervenção junto à Unesco quando esta não aprovou a candidatura a Patrimônio do Mundo do Parque Nacional do Senegal por exigir desse país "um comportamento igual ao que a Inglaterra ou a Alemanha teriam com relação a um local desses" (Magalhães, 
1985, p.85), pois via ser justamente a chancela da Unesco a possibilidade de se criarem as condições mínimas necessárias para a preservação do parque, e que o país "não tinha nem quem defendesse seu projeto na reunião da Unesco, nem quem fosse capaz de exprimir essa problemática convenientemente" (p.85-86).

\section{Digressões sobre o Valor Universal Excepcional}

Na avaliação sobre o Valor Universal Excepcional (VUE), urge uma reflexão crítica quanto ao conceito adotado de universal e até que ponto ele propicia o reconhecimento às diferenças culturais, de pensamento e de representação da diversidade humana e de sua produção sociocultural. Sua origem está relacionada às transformações ocorridas desde o Renascimento e com o humanismo, mas, principalmente, a partir do século XVIII, nas esferas socioculturais, e que vieram a caracterizar uma ruptura com os sistemas tradicionais ou a visão tradicional do mundo, com a inversão axiológica dos centros de referência do homem no mundo, conformando uma modernidade em que a cultura torna-se centro organizador do imaginário simbólico em substituição à fé (Vaz, 1997). Essa modernidade, por ser razão ativa, transformadora da natureza e criadora de um mundo humano, não abdica de espaço a outros e tem, em seu cerne, racionalidade e universalidade ocidentais construídas a partir das revoluções industrial e científica e, sobretudo, do iluminismo. O pensador espanhol contemporâneo Reyes Mate lembra-nos de que essa universalidade é particular e tem como base filosófica a razão greco-latina e germânica, ou cristã-germânica, para a qual toda realidade possui um sentido, porque há outras matrizes do pensamento nas quais o sentido nunca está dado, sendo a cultura europeia hegemônica não por ser a mais importante, mas por ser "o caput ou linha de frente do Espírito Universal". Afirma Reyes Mate (1997, p.16) que a "Europa sinaliza o caminho do progresso que todos os demais povos estão condenados a percorrer. Por isso quando a cultura inca ou asteca se aproximar do Espírito Universal, terá que se dissolver. O não europeu ou se integra ou se desvanece". ${ }^{4}$

Edward Said (1990), a partir do pensamento de Antonio Gramsci em seus Cadernos do cárcere, recupera o papel da cultura operando nos marcos da sociedade civil e a influência das ideias atuando por consenso e sobre as formas culturais e de ideias que predominam sobre outras, conformando um tipo de liderança que veio a ser denominada hegemonia, "um conceito indispensável para qualquer entendimento da vida cultural no Ocidente industrial", e prossegue afirmando que "o principal componente na cultura europeia é precisamente o que torna essa cultura hegemônica tanto na Europa quanto fora dela: a ideia de identidade europeia como sendo superior em comparação com todos os povos não europeus" (p.19).

O universal, o reconhecimento do outro e a diversidade cultural e étnica têm sido temas confrontados e transformados ao longo da história, principalmente a partir da segunda metade do século XX. Com o fim da Segunda Guerra Mundial, as reflexões subsequentes sobre os processos de descolonização na África e Ásia, sobre a busca por direitos humanos e por reconhecimento de diferentes grupos socioculturais e étnicos imprimiram nesses temas avanços e recuos em conjunturas diversas. Ou, como afirmou Aloisio Magalhães em depoimento prestado na terceira Reunião da Comissão Parlamentar de Inquérito para investigar a situação do Patrimônio Histórico e Artístico Nacional: 
Universal, meus senhores, não é igual; universal é o diversificado, é a interligação, é a interface de diversas coisas, da heterogeneidade que compõe o caráter de uma nação. E na medida em que nós, países pobres e novos, formos caindo nesse engodo de nos tornarmos iguais ... Que igualdade é essa que na verdade só faz diminuir a capacidade criativa, só faz diminuir a intensidade das relações, só faz diminuir a potencialidade de riquezas não conhecidas, que estão escondidas debaixo da frequência com que reiteradamente, no processo histórico, essas comunidades diversificadas vinham criando? (Magalhães, 1985, p.84).

Por sua vez, a Unesco realizou, em 1982, na Cidade do México, a "Conferência Mundial sobre Políticas Culturais" e, em seu informe final (Unesco, 1982), publicou diversas recomendações. Quanto à identidade cultural, em especial, o documento traz indicações relativas ao respeito, à valorização e à preservação das diferentes culturas, opondo-se a qualquer discriminação em relação à identidade cultural de outros países, regiões ou povos, preocupando-se principalmente, à época, em relacionar o direito à diversidade de expressão cultural aos direitos humanos e posicionando-se contra quaisquer mecanismos de dominação cultural. Em 2005, a Unesco aprovou em sua $33^{a}$ reunião, ocorrida em Paris, a Convenção Sobre a Proteção e Promoção da Diversidade das Expressões Culturais da Unesco (Unesco, 2007), cujo documento final afirma que a diversidade cultural é uma característica essencial da humanidade e constitui patrimônio comum desta, a ser valorizado e cultivado em benefício de todos. O que se observa, entretanto, é que os esforços por parte da Unesco pelo reconhecimento da alteridade ainda não se refletem no reconhecimento abrangente de bens culturais como patrimônio do mundo.

Sobre o valor, Choay (2001) lembra que, durante a Revolução Francesa e imediatamente a seguir, houve grande destruição e transferência de bens do clero e da corte francesa, gerada por necessidades econômicas e por motivações ideológicas ou mesmo por vandalismo. Por conseguinte, um dos primeiros atos jurídicos da Constituinte de 1789 foi colocar esses bens à disposição da nação, e, desse modo, o "valor primário do tesouro assim devolvido a todo o povo é econômico" (p.98). Esses bens, fossem antiguidades ou obras arquitetônicas, vieram a adquirir significados históricos e afetivos, mas o valor que sobressaiu como central a essa construção social e política da noção de patrimônio foi o valor nacional, de modo a subsidiar a ideia de nação, em que língua, costumes e cultura eram e são necessários à criação de laços identitários. Desse momento até hoje, os valores do patrimônio cultural são alvo de diferentes reflexões, como aquelas desenvolvidas por Alois Riegl (2014), quando convidado a redigir em 1903, após ser designado presidente da Comissão de Monumentos Históricos da Áustria, a obra O culto moderno dos monumentos: a sua essência e a sua origem, na qual discorre sobre atribuições de valor aos monumentos distintas do que se preconizava à época. Reconheceu haver valores de memória e de atualidade a ser atribuídos aos monumentos, distinguindo nos primeiros valor de antiguidade, valor histórico e valor de comemoração. Os segundos, dividiu em valores de uso, de arte, de arte relativo e de novidade. Até hoje, estudos e estudiosos se sobrepõem e se contrapõem na busca de definições sobre os valores dos bens culturais, reconhecendo-os com significados simbólicos, científicos, cognitivos, entre outros, e com a tendência atual apontando para: (a) o reconhecimento de uma diversidade de tipos de 
valores além dos ainda predominantes valores histórico e artístico; (b) o valor não ser algo intrínseco ao bem e, sim, uma atribuição dada por algum segmento da sociedade em determinados contexto e época; (c) a atribuição de valor a um bem cultural não poder ser exclusiva de especialistas, devendo considerar aqueles que dele usufruem ou com ele mantêm relações diversas, nas diferentes temporalidades.

Os significados estabelecidos a partir de um bem resultam de uma relação entre indivíduo ou comunidade com um objeto ou prática em um dado contexto e se expressam por meio de valores construídos socialmente e atribuídos como forma de explicitar essa condição. Essa relação entre bem cultural e indivíduo/comunidade se dá no modelo conceitual do homem como ser dialógico de Buber. Segundo Pinheiro (2004, p.94), para Martin Buber (s.d.), a condição de relação é ontológica, e a existência ocorre a partir da relação entre os homens, ou deles com seu meio, ou deles com Deus. O homem seria, então, antes de um ser social, um ser relacional, dialógico. Resulta dessa observação o fato de a atribuição de valores ser, em geral, decorrente de relações e significados construídos no tempo por algum grupo social em determinado lugar. Dizse em geral, pois, em determinados contextos, a lógica é invertida, e o valor antecede à atribuição de significados, como o verificado na ideia de nação e valor nacional, e à construção subsequente de significados identitários. Ou mesmo na centralidade em eleger a arquitetura colonial e moderna como patrimônio cultural nacional no caso brasileiro. Incerto, porém, é definir também como inversão lógica os valores atribuídos por especialistas a partir de critérios técnicos ditos imparciais. Conforme Chuva (2011, p.157), com a inserção do campo do patrimônio cultural em escala global depois da última Grande Guerra, principalmente após a aprovação da Convenção do Patrimônio Mundial em 1972, houve, a partir das décadas de 1970 e 1980, “um severo enfraquecimento dos estados e a expansão fantástica do poder transnacional do capital a ignorar as fronteiras nacionais". O que levou a novos valores e divisões que foram sendo constituídos e que "esmaeceram a ideia de nação em favor do fortalecimento de recortes identitários de outras naturezas" (p.157) como aqueles de ordem religiosa, étnica, ideológica, de gênero etc. Como nos diz Ulpiano Meneses (1996, p.93):

conviria observar que os valores que qualificam os objetos, práticas e ideias não são imanentes, não surgem a partir desses mesmos objetos, práticas e ideias. Aquilo, por exemplo, que chamamos de bens culturais não tem em si sua própria identidade, mas a identidade que os grupos sociais lhe impõem. Assim, para falar da arte - que é um campo que não esgota a cultura, mas permite compreendê-la em aspectos cruciais -, pode-se afirmar, por exemplo, que não existem valores estéticos universais e permanentes.

Entretanto, o debate descrito anteriormente se refere ao valor atribuído ao bem cultural, o que a priori o reduz a parte de uma reflexão maior, que é aquela sobre o valor como atributo socialmente construído nas diferentes esferas da ação e do cotidiano humano, produzida desde a filosofia clássica até nossa contemporaneidade, como nos revela o pensamento de Agnes Heller. A filósofa nos diz que "o decurso da história é o processo de construção dos valores, ou da degenerescência e ocaso desse ou daquele valor", e que este é "tudo aquilo que faz parte do ser genérico do homem e contribui, direta ou mediatamente, para a 
explicação desse ser genético" (Heller, 2016, p.17). É, pois, o valor uma categoria ontológicosocial, sem possuir "objetividade natural (apenas pressupostos ou condições naturais), e sim objetividade social" (p.18). Considera-o "como tudo aquilo que produz diretamente a explicitação da essência humana ou é condição de tal explicitação" (p.23), mas observa que o valor, uma vez obtido ou dado pela humanidade, não pode ser posteriormente extinto em sua totalidade, e em casos de perda de algum estágio antes alcançado, persiste a existência desse valor como possibilidade. Por não se perder de modo absoluto, haverá sempre a probabilidade de ressurreição, e seu declínio, mesmo que efetivo num dado momento, será relativo do ponto de vista histórico-universal. A impossibilidade de perda plena de algum valor, de ele residir de modo latente, adormecido, mesmo que decadente, reforça a compreensão de que a humanidade sempre produziu valores ao longo do tempo e em todos os lugares onde esteve. Valores que tornaram e fazem possível convivermos socialmente, mas simultaneamente são resultados e fomentadores de relações dialógicas e responsáveis com nosso planeta, conosco e com o outro. Esse pensamento, aplicado aos valores de um bem cultural, evidencia questões sobre a relevância de quem os atribui, de quem os avalia, diante de múltiplas temporalidades.

Uma reflexão que contempla a variedade de sentidos nas concepções de universal e de valor pode ser explicitada por meio de textos que distintamente abordam questões sobre as diásporas africana e judaica, mas que nos permitem discutir a questão do distanciamento e de o território propiciar significados e valores identitários distintos. Munanga (2012), ao abordar os discursos atuais sobre a identidade negra no Brasil, observa que eles aparecem confusos e reflete sobre a relevância da memória e da territorialidade na construção de identidades comunitárias. Pelo fato de essa identidade compreender um conjunto de traços distintos, implica também o reconhecimento de uma grande diversidade, o que faz Munanga pensar que o único traço comum a todos os negros seria a situação de exclusão. Reconhece que a busca dessa identidade negra da diáspora africana é um imperativo ao grupo. Nesse sentido, entende a importância do território e da territorialidade como elementos na construção dessa identidade coletiva, ou seja, "ter a consciência de pertencer a uma única ancestralidade que se materializa não pelos 'mortos comuns', mas sim pela consciência de ter um território físico comum" (Munanga, 2012, p.16), e, pois, essa terra é a África, como continente negro, "que sobrou como lembrança indestrutível contínua a ser recriada, reinventada e idealizada em todos os discursos identitários da diáspora" (p.17). No seu discurso, reconhece que são aqueles territórios referentes aos lugares de resistência religiosa, ou aqueles conquistados coletivamente e que originaram os quilombos, como constitutivos comuns junto à terra, África, dessa identidade.

Por sua vez, Mate (1997), ao discorrer sobre ser judeu e estar na história, reflete sobre a relação, distinta de outros povos, que os judeus mantêm com os elementos fundamentais da construção de identidades nacionais, como a terra, a língua e a lei. A relação do povo judeu com a terra é de ausência, visto que o exílio o libera do enraizamento ao solo pátrio e se configura tanto como uma categoria política quanto ontológica, marcando "a distância respectiva ao que a terra significa (própria história, próprio Estado) até o ponto em que até em sua própria terra o judeu estaria em exílio" (Mate, 1997, p.165), pois está solicitado a abandonar a sua terra e ir à Terra Santa. 
Na Grécia antiga, em Odisseia, de Homero (2011), Ulisses sai de sua terra, Ítaca, numa viagem longínqua e por tempo indeterminado, e sua aventura pelos lendários mares ocorre após deixar Troia, mas a ideia do retorno é o que o mantém vivo, o que o faz avançar, o que o leva em sua perdição a se encontrar, numa bela metáfora da ruptura do homem com o mito e seu encontro com a razão, como refletem Horkheimer e Adorno (1985). Há, portanto, o vínculo com a sua terra, e tudo que ela possa representar, mesmo que o distanciamento seja sua realização. É, pois, uma relação próxima, mas ainda diversa à da diáspora africana com a territorialidade, pois esta não alimenta o retorno físico à terra-mãe. Entretanto, na perspectiva judaica, Abraão parte de sua terra natal para uma terra prometida, desfazendo-se dos vínculos com o que foi deixado para trás. As diásporas relatadas tanto por Munanga como por Mate apresentam apropriações e significados distintos de território e terra, mas ambas se apresentam de modo comum como elementos nostálgicos e de memória, e, ainda que por formas diferentes, como constituintes de identidades, refletindo apropriações singulares de valores e do conceito de universal. Como se ater a fronteiras demarcadas na avaliação de um bem cultural como de valor universal, se a África, mantendo-nos restritos aos exemplos citados anteriormente, não contém uma matriz de pensamento única, uma vez que é múltipla cultural e etnicamente, encerrando razões diversas como as que se movem a partir da ancestralidade? Como não considerar racionalidades distintas como as do pensamento judeu, como nos relata Mate (1997), sobre o universal desde sua marginalidade, distanciado da história, em que o valor da diversidade e da multiplicidade se sobrepõe ao da unidade?

\section{Sobre as lacunas de representação e o patrimônio cultural da saúde}

Desde a aprovação da Convenção para a Proteção do Patrimônio Mundial, a Unesco tem procurado ampliar o espectro de tipos de patrimônios reconhecidos como de valor excepcional universal, na perspectiva de reconhecimento da diversidade humana e de sua produção sociocultural. Com isso, foram promovidos novos temas e categorias para bens do patrimônio mundial, como paisagens culturais, itinerários, patrimônio industrial, desertos, locais costeiros e pequenas ilhas. Nas diversas categorias do patrimônio mundial, até 2019, temos o total de 1.121 bens distribuídos em 167 dos 193 países signatários da convenção, do seguinte modo: Natural - 213; Cultural - 869; Misto - 39. Entre esses, há 53 bens em Risco e 39 Transfronteiriços. Desse total ainda se destacam 444 bens que podem ser tratados também por temas, como: Florestas - 90; Marinha e Costeira - 49; Cidades - 192; Paisagens Culturais - 113.

Importante fator de análise é a ideia de patrimônio comum da humanidade, como apontada por Boaventura Santos (1998). Segundo ele, temos vários exemplos de patrimônios comuns com a ideia de compartilhamento por toda a humanidade, como a Antártica, a Lua, os oceanos, possuindo tratados que regulam seu uso pelas nações, ou seja, para seus usos, todos que subscrevem esses acordos deveriam ser ouvidos. Independentemente desses instrumentos jurídicos internacionais, mais relevantes são os aspectos simbólicos, culturais da humanidade, mesmo considerando as questões econômicas e políticas envolvidas nas disputas desses temas.

Esses "macropatrimônios" colocam questões desafiadoras sobre como essas dimensões simbólicas podem contribuir para uma ideia de algo comum a toda a humanidade e sobre 
os seus recursos provenientes serem compartilhados de forma a todos poderem usufruir de seus benefícios, reforçando uma cultura de educação e valorização patrimonial para toda a humanidade. Nesse sentido é que a ideia de patrimônio do mundo pode assumir várias escalas, sob maior ou menor influência de situações políticas, questões econômicas e disputas de hegemonia. A observação de como caminham os reconhecimentos dos patrimônios das regiões do mundo diante de fatores sociais, econômicos e geopolíticos é determinante na representação do capital cultural dessas regiões e na revisão de rumo, estratégias e temáticas na escolha desses patrimônios mundiais. Permite avaliar o quanto as disputas de hegemonia no campo do simbólico podem estar vinculadas às contendas econômicas, à contribuição financeira de países e regiões, impulsionando ou reprimindo temas conforme seus próprios interesses.

O desafio de reconhecimento da diversidade clama também pela representação de patrimônios simbólicos em áreas tão próximas ao homem hodierno como indústria, ciência e tecnologia, universidades e instituições de educação, o que ganha contornos críticos principalmente ao lembrarmos que a Unesco é uma agência das Nações Unidas voltada para a educação, ciência e cultura. O que se observa, porém, é a pouca visibilidade da educação e da ciência, sem o destaque dispensado às novas categorias e temas, e inconsistência de resultados quando se pesquisa quais são os patrimônios mundiais representativos dessas áreas. No tocante ao tema da ciência, por exemplo, estima-se que haja aproximadamente uma centena de bens que poderiam ser considerados representativos, mas que estão dispersos, avaliados muitas vezes por critérios que não enfatizam sua relevância pela produção da ciência, do conhecimento ou de algum desenvolvimento tecnológico. Nas ferramentas de busca do sítio oficial na web do WHC (Unesco, 2019a), encontram-se números e resultados controversos sobre bens inscritos como patrimônio mundial relacionados a ciência, educação, indústria, tecnologia. Por exemplo, uma busca por "science properties" na categoria "world heritage properties" apresentou 37 resultados, que incluíam desde "obras de Antonio Gaudí" (pelo uso da tecnologia) até "Ferrara, cidade da Renascença e o delta do Pó". Por outro lado, houve resultado nulo quando utilizada a ferramenta de busca avançada com palavras-chave existentes em seu vocabulário controlado (como "science", "technical", "science for a sustainable future", "teleconference", "telephone"). A busca por "technological development" exibiu 16 bens, sendo 14 culturais e dois mistos, incluindo um transfronteiriço e um em risco, em 14 países.

Na busca que apresentou os 37 bens ligados à ciência, não foram relacionados bens como o Complexo Casa-Oficinas-Museu Plantin-Moretus, uma gráfica e editora datada dos períodos renascentista e barroco, situada na Antuérpia, que é considerada uma das três principais cidades do início da impressão europeia, juntamente com Paris e Veneza, e está associada à história da invenção e difusão da tipografia; o Arco Geodésico de Struve-Belarus, relevante para estabelecer o tamanho e a forma exatos do planeta, um passo importante no desenvolvimento das ciências da Terra e no mapeamento topográfico e um exemplo extraordinário de colaboração entre cientistas de diferentes países; ou o Jodrell Bank Observatory, inscrito em 2019 como patrimônio do mundo. Localizado em uma área rural do noroeste da Inglaterra, o Jodrell Bank é um dos observatórios de radioastronomia mais importantes do mundo, ilustrando a transição da astronomia óptica tradicional para a radioastronomia. 
Esse levantamento ratifica o observado anteriormente por Lourenço e Wilson (2013, p.748) quanto ao limitado número de bens relacionados à ciência classificados como patrimônio do mundo, e, "como um exemplo particularmente ilustrativo", o número de apenas três bens qualificados à época como patrimônio científico conforme os atributos definidos em seu artigo, num universo de quase mil bens indicados como patrimônio do mundo. As autoras produzem importante reflexão sobre a definição e o escopo do que se poderia compreender como patrimônio científico, ou patrimônio da ciência, entendendo inclusive como diversa a sua nominação, caracterizando-o como bastante complexo, multidimensional e com mais dificuldade de definição que outras categorias de patrimônio cultural ou mesmo à frente da diversidade do patrimônio natural. Transitando na interseção do "mundo da ciência e o mundo do patrimônio (cultural)", ambos são dinâmicos e envolventes, mas com seus "valores, tradições, e práticas, ... consideravelmente diferentes e geralmente contraditórios por natureza" (Lourenço, Wilson, 2013, p.745). As possíveis contradições que resultem dessa interseção trarão também inúmeras potencialidades de reconhecimento do fazer humano, para além dos artefatos e das coleções científicas, envolvendo construções, paisagens, saberes e temporalidades múltiplas, não se restringindo ao valor histórico e possuindo também valores cognitivos e de contemporaneidade. Trarão também, por sua abrangência, a possibilidade de fragmentação e indefinição como campo disciplinar.

As investigações por bens relacionados à educação pelo sistema de busca avançada no sítio do WHC com as palavras-chave indexadas "education/ éducation/ education centre", tiveram ocorrências nulas. Noutro campo de busca no mesmo sítio ocorreram apenas seis resultados, sem exemplos como o da Universidade de Coimbra-Alta e Sofia, um patrimônio mundial que influenciou instituições de ensino do antigo império português, com uma tipologia urbana específica, ilustrando a integração abrangente de uma cidade e sua universidade, que foi, posteriormente, reinterpretada em várias universidades.

Quanto à saúde, entretanto, nada foi obtido. Não houve sua menção nos registros relacionados à ciência, tecnologia, educação ou indústria, nem se encontraram palavraschave como "health", "santé" ou termos correlatados no vocabulário controlado da pesquisa avançada. Também não houve ocorrência na pesquisa por hospitais, à exceção de um resultado quando pesquisado por "hospital building", com o Santuário de Asklepios em Epidauro, um santuário ao deus da medicina e que se desenvolveu a partir de um culto antigo a Apolo. Não aparece, contudo, o Hospital de Sant Pau em Barcelona, que foi inscrito juntamente com o Palácio da Música Catalã, como duas das melhores contribuições para a arquitetura de Barcelona pelo arquiteto catalão Lluís Domènech i Montaner. Possivelmente por sua declaração como patrimônio mundial não haver considerado sua relevância como arquitetura hospitalar ou como patrimônio relacionado à saúde, e sim por ser exemplar da arquitetura modernista catalã. $\mathrm{O}$ que se pode presumir de antemão é que, mesmo existindo patrimônios mundiais com significados representativos a ciência, tecnologia, educação e saúde, não são de fácil identificação como tais, estão sem visibilidade e são pouco valorizados.

A importância da saúde no identitário social deve ser considerada uma ação de mais de 50 anos no campo do patrimônio, que vem sendo ampliada e tendo seus bens incorporados, 
desdobrando-se, assim como todas as ações relativas ao patrimônio cultural, de modo desigual em diferentes países. Se há países como a França, onde desde 1958 a Sociedade Francesa de História dos Hospitais busca inventariar e valorizar o patrimônio dessas instituições (Serres, 2015), em outros, a valorização desse patrimônio é tão diminuta como a dada às questões da própria saúde da população. Vale ressaltar, no entanto, quanto ao bem cultural da saúde, ensaios que internacionalmente surgem "ligados diretamente ao valor simbólico a ele conferido pelas comunidades nas quais está inserido" (Sanglard, Costa, 2008, p.25), como a experiência ocorrida no Chile, influenciadora no Brasil na preservação do patrimônio cultural da saúde, a partir de mobilização da população e dos funcionários contra a demolição do antigo Hospital San José. Ação pioneira, que serviu, segundo Sanglard e Costa (2008, p. 25), como inspiração para a criação da Rede Latino-americana de História e Patrimônio Cultural da Saúde, integrada à Biblioteca Virtual de Saúde, à qual o Brasil se filiou em 2005, por meio de seu Ministério da Saúde e tendo a Fundação Oswaldo Cruz (Fiocruz) como coordenadora, resultando na produção de conhecimento científico e de inventários sobre os acervos relativos ao tema.

Cabe refletir sobre diferentes conceitos de cultura, entendendo-a como produtos comportamentais, espirituais e materiais da vida social humana, conforme definida no século XIX por Edward Tylor. A cultura se estabelece a partir de atos e ações dos seres humanos pela busca do sentido de suas vivências no mundo e de "redes de significados" (Geertz, 2008), como um texto a ser interpretado por aqueles que querem compreender as diferentes narrativas, construindo uma capacidade de simbolizar. É algo que acontece nas relações entre as pessoas nos ambientes públicos por serem espaços que possibilitam o compartilhamento dos sentidos dessa teia de significados produzidos em nosso cotidiano. $\mathrm{Ou}$, como definida pela Unesco, que a tem em toda sua diversidade, como fundamento da identidade, da energia e das ideias criativas dos povos e fator de desenvolvimento e coexistência em todo o mundo. Definição reafirmada pela Convenção sobre a Proteção e Promoção da Diversidade das Expressões Culturais de 2007, que a descreve como o conjunto dos traços distintivos espirituais e materiais, intelectuais e afetivos que caracterizam uma sociedade ou um grupo social, abrangendo, além da produção artística, os modos de vida, as formas de viver em comunidade, os sistemas de valores, as tradições e as crenças, assumindo formas diversas ao longo do tempo e do espaço.

Inequívoco, portanto, interpretar a saúde, as práticas de saúde, as ciências da saúde, os equipamentos destinados à produção da saúde e as relações sociais cotidianas com a saúde como alguns dos elementos constituintes da cultura. Por outro lado, o conceito ampliado de saúde recupera a importância das dimensões econômica, política, social e cultural na produção da saúde, entendendo que ela é produzida nas relações do indivíduo ou de uma comunidade com os meios físico, social e cultural com os quais convivem ao longo de suas vidas. Há uma potente relação, pouco evidenciada e trabalhada, entre cultura e saúde, dois campos vitais nas vidas, no cotidiano e nas relações humanas.

A Unesco não atua na área da saúde, mas essa questão possibilita cooperações inusitadas para atender a mútuos interesses, abrindo assim potenciais ações junto à Organização Mundial da Saúde (OMS) e à Organização Pan-americana da Saúde (Opas) para pensar conjuntamente temas que relacionem ciências e saúde com o patrimônio cultural, reunindo 
produtos e registros dos processos de pesquisa, produção e assistência à saúde. A relação entre cultura e saúde engloba ainda diferentes campos disciplinares das ciências humanas e sociais aplicadas ao patrimônio constituído e aos acervos de conhecimento, vinculados às trajetórias de instituições e atores sociais das ciências biomédicas e da saúde. Para tanto, hão de ser consideradas potenciais elos as instituições centenárias e de referência nos campos da saúde, da memória e da história, que atuam fortemente na preservação de seu patrimônio cultural. Há que respeitar, por exemplo, o vasto campo de atuação da Fiocruz, além da sua história no campo da saúde, com interfaces entre a produção científica da instituição e as vulnerabilidades sociais da realidade brasileira e regional. Há que lembrar, ainda, que a Fiocruz é reconhecida com diversas premiações nacionais por sua atuação na preservação de seu patrimônio cultural, pela vasta produção científica e pelas diferentes ações de educação na área, que vão desde um programa de pós-graduação a uma oficina-escola para qualificação de profissionais nos ofícios da conservação e restauração de bens culturais.

A Fiocruz, possuidora de forte reputação junto à sociedade e à comunidade científica nacional e internacional, ${ }^{5}$ celebrou em 2018 o centenário de finalização do Pavilhão Mourisco e em 2020 comemora seus 120 anos de existência como uma das principais instituições públicas de ciência, tecnologia e inovação em saúde da América Latina. O Núcleo Arquitetônico Histórico de Manguinhos, conjunto originário dessa instituição, construído para abrigar a produção de soros e vacinas, ensino e pesquisa em ciências e saúde, tem no Pavilhão Mourisco, ou Castelo, sua principal edificação, que, originalmente, abrigava laboratórios, biblioteca e museu, e mantém-se como sede e maior símbolo da Fiocruz.

Conforme identificado por Lourenço e Wilson (2013), o patrimônio científico pode ser encontrado em todas as instituições de ensino e pesquisa, independentemente de seu tamanho ou expressão. Tipicamente, há nessas instituições uma falta de consciência sobre seus bens culturais que se expressa pela ausência de procedimentos organizados e de políticas de gestão, conservação e acesso a seus acervos. A Fiocruz, que possui uma diversidade de acervos culturais constituídos e preservados desde sua origem (arquitetônicos e urbanísticos, arqueológicos, arquivísticos, bibliográficos, biológicos, e museológicos), reconhecidos nacional e internacionalmente, entendeu a necessidade de estabelecer uma gestão integrada de seus acervos culturais, por isso desenvolveu e aprovou, em 2018, sua Política de preservação dos acervos científicos e culturais ${ }^{6}$ (Fiocruz, 2018), ${ }^{7}$ tomando como base o conceito ampliado de patrimônio cultural tal como estabelecido na Constituição brasileira de 1988. Essa ação reflete sua postura quanto a seus acervos, podendo-se afirmar existir, nessa instituição, uma cultura de preservação e valorização de seu patrimônio cultural e de sua memória, expressa por iniciativas históricas como a de ser proponente do primeiro processo de tombamento pelo Instituto de Patrimônio Histórico e Artístico Nacional (Iphan), em 1980, de três edificações ${ }^{8}$ que compunham o Núcleo Arquitetônico Histórico de Manguinhos. O tombamento como patrimônio nacional foi expedido em 1981. Posteriormente, em 1985, a Fiocruz encaminhou nova solicitação ao Iphan pela extensão do tombamento, com a inclusão tanto da área verde existente ao redor dessas edificações quanto de outras edificações do período eclético.

A Fiocruz propôs ao Iphan, em dezembro de 2018, a inclusão do Pavilhão Mourisco na Lista Indicativa do Brasil a Patrimônio Mundial por acreditar ser ele possuidor de valor 
universal excepcional por seu significado simbólico na ação de saúde pública no Brasil, na América Latina e no âmbito mundial; na construção de uma identidade nacional com base na ciência e na tecnologia; na representação de uma história do desenvolvimento científico da região; e como constitutivo de um lugar de memória da saúde e marco referencial do fazer científico. A possibilidade encerrada na concretização dessa candidatura como patrimônio mundial deve ser vista como a materialização de uma representação ampliada da diversidade cultural e de áreas e temas até então com sub-representação ou pouca visibilidade como as da saúde e das ciências.

\section{Considerações finais}

Os esforços da Unesco em revelar e valorizar a diversidade cultural dos diferentes povos e nações são cada vez mais necessários diante da intolerância e beligerância, assim como são necessárias suas autoavaliações quanto à efetividade de suas diretrizes e estratégias. A disponibilização de dados por meio de seu portal na internet é um instrumento precioso para que mais pesquisas ocorram, com perspectivas diversas que envolvam questões sociais, econômicas, culturais e outras, contribuindo para que haja maior pluralidade representativa nos patrimônios mundiais, compreendendo-os como parte relevante de um campo de disputas geopolíticas e de hegemonias. Constata-se, porém, uma incipiente reflexão crítica sobre o patrimônio do mundo, quanto à sua representatividade e apropriação social, em todo o processo de candidatura e inscrição de um bem cultural nessa iniciativa. Ainda que se verifiquem problemas na sistematização de dados e informações, e nas ferramentas de busca avançada, deve-se prosseguir no seu aprimoramento, no acesso aberto aos dados produzidos, na adoção de vocabulário controlado e atualizável, bem como em maior visibilidade das informações produzidas. Faz-se necessário o investimento para suprir lacunas ainda verificadas na comunicação e na valorização do papel das comunidades, tal como previsto nos Cinco C.

Por outro lado, a questão não é tornar imperativo o reconhecimento dos patrimônios culturais relativos às ciências e à saúde como temas, ou muito menos como categorias, ainda que a própria Unesco seja proponente de novos temas e categorias como estratégia inclusiva da diversidade cultural. É, sim, dar mais visibilidade e atenção às representações de nossa contemporaneidade e aos caminhos que nos trouxeram a ela, que passam por áreas como religião, arte, história, arquitetura e urbanismo, mas acontecem também pela educação, ciência, tecnologia e saúde, notadamente sub-representadas nos atuais patrimônios do mundo. Cabe observar que, para a submissão de candidatura à Unesco, o bem cultural deve antes fazer parte da lista tentativa do Estado-parte, e, para isso, pressupõe-se como condição prévia que esse bem seja já considerado patrimônio cultural nacional. O que nos coloca a possibilidade de ser a baixa representação de patrimônios relativos às ciências e à saúde como patrimônio do mundo um reflexo de uma incipiente e passiva postura dos Estados-parte no reconhecimento de seus patrimônios científicos, tecnológicos e da saúde e na escuta à sociedade. Cabe, entretanto, também considerar o papel indutor que a Unesco pode exercer na valorização e no reconhecimento desse expressivo patrimônio da humanidade, influenciando sobremaneira as nações quanto a valorização e visibilização de sua memória e seu patrimônio cultural relativos ao fazer científico. 
A preservação e a valorização do patrimônio cultural das ciências e da saúde devem ser encaradas como um desafio a ser enfrentado com o estímulo a candidaturas a patrimônio do mundo de bens representativos. Sendo esse tipo de bem cultural repleto de valores simbólicos junto a diferentes comunidades, torna-se o elo para o estabelecimento de relações promissoras e solidárias entre diferentes regiões, incorporando cultura e saúde como elementos estratégicos à redução das iniquidades; para a promoção de políticas nacionais e internacionais de desenvolvimento sustentável, bem como da diversidade cultural; e para o exercício dos direitos culturais e humanos.

\section{NOTAS}

${ }^{1}$ Tradução nossa de "Operational Guidelines for the Implementation of the World Heritage Convention". Como a versão em português desse documento presente no site do World Heritage Centre é informada como não oficial, utilizaremos a versão oficial em inglês como nossa referência. Iremos nos referir a esse documento como Orientações Técnicas para Aplicação da Convenção do Patrimônio Mundial, ou simplesmente como Orientações Técnicas.

2 Os objetivos estratégicos atuais, também referidos como "os cinco C", são os seguintes: "1. Reforçar a Credibilidade da Lista do Patrimônio Mundial; 2. Assegurar a Conservação efetiva dos bens do patrimônio mundial; 3. Promover o desenvolvimento de Competências efetivas nos Estados-partes; 4. Incrementar a sensibilização do público, a participação e o apoio ao Patrimônio Mundial por meio da Comunicação. 5. Valorizar o papel das Comunidades na aplicação da Convenção do Patrimônio Mundial" (Unesco, 2017, p.13).

${ }^{3}$ Os cinco primeiros países, em ordem decrescente: China (55), Itália (54), Espanha (48), Alemanha (46) e França (45) (Unesco, 2019a).

${ }^{4}$ Nessa e nas demais citações de textos em outros idiomas, a tradução é livre.

${ }^{5}$ A Fiocruz realizou, em 2014, uma pesquisa sobre sua reputação que foi apontada como positiva por 73\% da população em geral. Nesse mesmo ano, o Centro de Gestão e Estudos Estratégicos e o então Ministério da Ciência Tecnologia e Inovação realizaram uma pesquisa nacional sobre a percepção pública da ciência e tecnologia, em que Oswaldo Cruz foi o cientista mais lembrado por $40 \%$ dos entrevistados, e a Fiocruz foi a instituição de ciência mais lembrada por 19,2\% dos entrevistados, ficando ambos em primeiro lugar nessas questões. Somam-se a essas pesquisas o reconhecimento da Fiocruz como melhor instituição de saúde pública no mundo em 2006 pelo World Federation of Public Health Association, e como melhor instituição de pesquisa no Brasil em 2014 pela Universidade de Leiden (Holanda).

${ }^{6} \mathrm{O}$ uso da expressão "acervos científicos e culturais", embora possa ser questionável se aplicado o conceito de ser o fazer científico uma ação humana, e, portanto, cultural, estrategicamente foi muito importante para tornar possível o desenvolvimento e a aplicação dessa política, pois aproximou os cientistas e curadores das coleções científicas dos profissionais envolvidos com a preservação patrimonial. Cabe ressaltar que o processo de construção dessa política seguiu o caminho da gestão democrática, o que implicou longo e rico processo participativo dos trabalhadores da instituição na elaboração e aprovação do documento.

${ }^{7}$ Essa política estabelece os princípios gerais, diretrizes e objetivos que orientam as atividades de constituição, preservação, gestão integrada e acesso a seus acervos científicos e culturais.

${ }^{8}$ A saber: o Pavilhão Mourisco, a Cavalariça e o Pavilhão da Peste.

\section{REFERÊNCIAS}

BUBER, Martin.

Eu e tu. São Paulo: Centauro. s.d.

CHOAY, Françoise.

A alegoria do patrimônio. São Paulo: Estação

Liberdade; Editora da Unesp. 2001.
CHUVA, Márcia Regina Romeiro.

Por uma história da noção de patrimônio

cultural no Brasil. Revista do Patrimônio Histórico e Artístico Nacional, n.34, p.147-165. 2011.

GEERTZ, Clifford. A interpretação das culturas. Rio de Janeiro: LTC. 2008. 
FIOCRUZ.

Fundação Oswaldo Cruz. Política de preservação dos acervos científicos e culturais da Fiocruz. Rio de Janeiro: Fundação Oswaldo Cruz, Casa de Oswaldo Cruz. Disponível em: <https:// portal.fiocruz.br/sites/portal.fiocruz.br/files/ documentos/politica_de_preservacao_dos_ acervos_cientificos_e_culturais_da_fiocruz digital_2018.pdf>. Acesso em: 25 out. 2019. 2018.

FIANKAN-BOKONGA, Catherine.

Uma resolução histórica para proteger o patrimônio cultural. O Correio da UNESCO, p.710. Disponível em: <https://unesdoc.unesco.org/ ark:/48223/pf0000259898_por>. Acesso em: 21 jul. 2019. out.-dez. 2017.

GUEDES, Maria Tarcila Ferreira.

A proteção dos bens culturais em tempos de guerra e de paz: a participação brasileira na Conferência de Haia, no Pacto de Röerich e na Convenção de Haia. Anais do Museu Paulista: História e Cultura Material, n.26, e19. epub 14 nov., p.1-31. Disponível em: <http://www.scielo. br/scielo.php?script=sci_arttext\&pid=S010147142018000100409\&lng=en\& $\mathrm{nrm}=$ iso $>$. Acesso em: 21 jul. 2019. 2018.

HELLER, Agnes.

O cotidiano e a história. Rio de Janeiro: Paz e Terra. 2016.

\section{HOMERO.}

Odisseia. São Paulo: Penguin Classics; Companhia das Letras. 2011.

HORKHEIMER, Max; ADORNO, Theodor W. Dialética do esclarecimento: fragmentos filosóficos. Rio de Janeiro: Jorge Zahar. 1985.

INSTITUTO RÖERICH...

Instituto Röerich da Paz e Cultura do Brasil. Pacto Röerich. Disponível em: <https://roerich. org.br/nicholas-roerich/>. Acesso em: 23 jul. 2019. s.d.

LOURENÇO, Marta; WILSON, Lydia. Scientific heritage: reflections on its nature and new approaches to preservation, study and access. Studies in History and Philosophy of Science, v.44, n.4, p.744-753. 2013.

MAGALHÃES, Aloisio.

E Triunfo? A questão dos bens culturais no Brasil. Rio de Janeiro: Nova Fronteira; Brasília: Fundação Pró-Memória. 1985.

MATE, Reyes.

Actualidad de pensadores judíos olvidados. Barcelona: Anthropos. 1997.

MUNANGA, Kabengele.

Território e territorialidade como fatores constitutivos das identidades comunitárias no Brasil: caso das comunidades quilombolas. In: Nogueira, João Carlos; Nascimento, Tânia Tomázia (Org.). Patrimônio cultural, territórios e identidades. Florianópolis: Atilènde. p.15-20. 2012.

MENESES, Ulpiano T. Bezerra de.

Os usos culturais da cultura: contribuição para uma abordagem crítica das práticas e políticas culturais. In: Yazigi, Eduardo (Org.). Turismo, espaço, paisagem e cultura. São Paulo: Hucitec. p.88-99. 1996.

PINHEIRO, Marcos José de Araújo.

Museus, memória e esquecimento: um projeto da modernidade. Rio de Janeiro: E-papers. 2004.

RIEGL, Alois.

O culto moderno dos monumentos: a sua essência e a sua origem. São Paulo: Perspectiva. 2014.

SAID, Edward Wadle.

Orientalismo: o Oriente como invenção do Ocidente. São Paulo: Companhia das Letras. 1990.

SANGLARD, Gisele; COSTA, Renato da GamaRosa.

Memória, história e patrimônio cultural da saúde: uma história possível. In: Porto, Ângela. (Org.). História da saúde no Rio de Janeiro: instituições e patrimônio arquitetônico (18081958). Rio de Janeiro: Editora Fiocruz. p.17-28. 2008.

SANTOS, Boaventura de Sousa. Tempo, códigos barrocos e canonização. Revista Crítica de Ciências Sociais, n.51, p.320. Disponível em: <https://ces.uc.pt/myces/ UserFiles/livros/81_Tempo\%20Codigos\%20 Barrocos_RCCS51.pdf>. Acesso em: 20 jul. 2019. 1998.

SERRES, Juliane Conceição Primon. Preservação do patrimônio cultural da saúde no Brasil: uma questão emergente. História, Ciências, Saúde - Manguinhos, v.22, n.4, p.14111426. 2015.

\section{UNESCO.}

Organização das Nações Unidas para a Educação, a Ciência e a Cultura. World Heritage List Statistics. Disponível em: <https://whc.unesco.org/en/list/ stat/\#s10>. Acesso em: 19 jul. 2019. 2019a.

UNESCO.

Organização das Nações Unidas para a Educação, a Ciência e a Cultura. Global strategy. Disponível em: <https://whc.unesco.org/en/ globalstrategy/>. Acesso em: 20 jul. 2019. 2019b.

\section{UNESCO.}

Organização das Nações Unidas para a Educação, a Ciência e a Cultura. Operational guidelines for the implementation of the World 
Heritage Convention. Paris: Unesco. Disponível em: <https://whc.unesco.org/en/guidelines>. Acesso em: 19 jul. 2019. 2017.

UNESCO.

Organização das Nações Unidas para a Educação, a Ciência e a Cultura. Convenção sobre a proteção e promoção da diversidade das expressões culturais. Brasília: Unesco. Disponível em: <http://unesdoc.unesco.org/ images/0015/001502/150224por.pdf $>$. Acesso em: 19 jul. 2019. 2007.

\section{UNESCO.}

Organização das Nações Unidas para a Educação, a Ciência e a Cultura. Conferencia mundial sobre las políticas culturales: informe final. Ciudad de México. Disponível em: <https://unesdoc.unesco.org/ark:/48223/ pf0000052505_spa>. Acesso em: 19 jul. 2019. 1982.

VAZ, Henrique Claudio de Lima.

Escritos de filosofia III: filosofia e cultura. São Paulo: Loyola. 1997.

\section{$\rightarrow \rightarrow \rightarrow<<<$}

